Supplement of Nat. Hazards Earth Syst. Sci., 20, 1203-1217, 2020

https://doi.org/10.5194/nhess-20-1203-2020-supplement

(c) Author(s) 2020. This work is distributed under

the Creative Commons Attribution 4.0 License.

(c) (1)

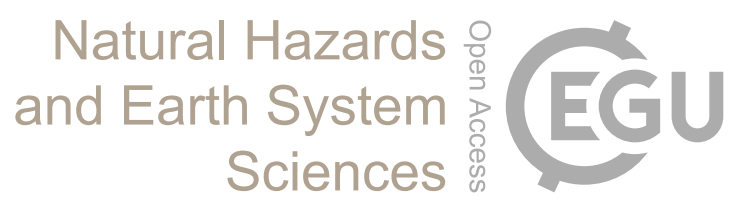

Supplement of

\title{
Analysis of properties of the 19 February 2018 volcanic eruption of Mount Sinabung in S5P/TROPOMI and Himawari-8 satellite data
}

Adrianus de Laat et al.

Correspondence to: Adrianus de Laat (laatdej@knmi.nl)

The copyright of individual parts of the supplement might differ from the CC BY 4.0 License. 

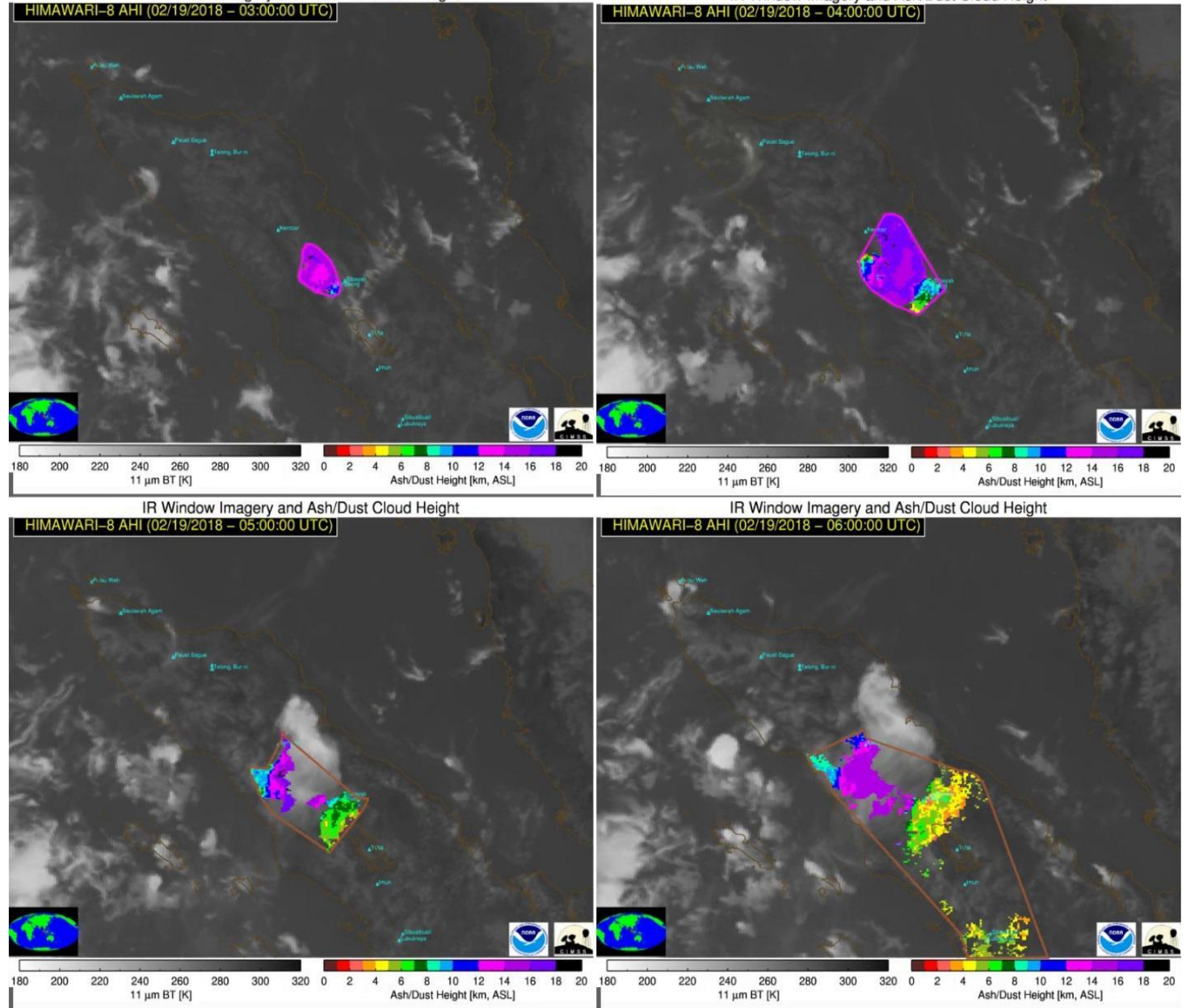

IR Window Imagery and Ash/Dust Cloud Height

IR Window Imagery and Ash/Dust Cloud Height

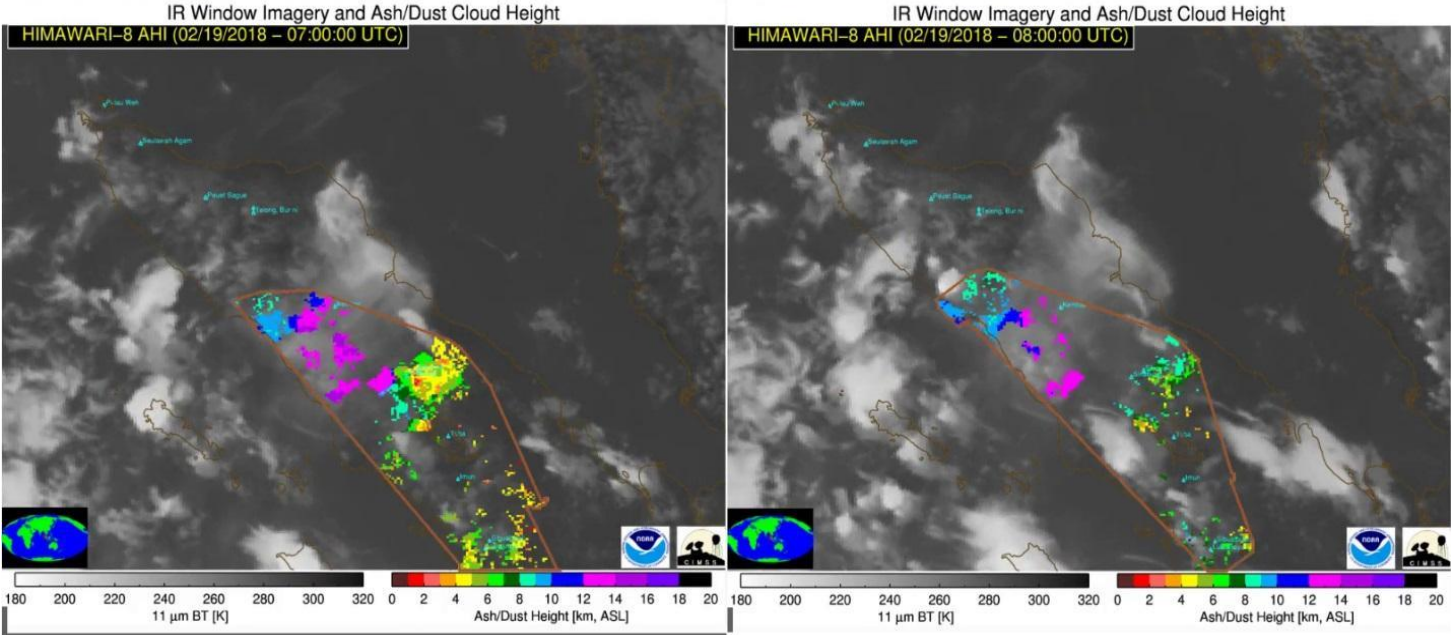


Figure S1. Hourly HIMAWARI-based brightness temperatures $(11 \mu \mathrm{m})$ and ash/dust heights on 19 February 2018 over Sumatra between 03:00-08:00 UTC. Ash dust heights from NOAA/CIMSS, imagery obtained from the NOAA/CIMSS

10 Volcanic Cloud Monitoring Web Portal (https://volcano.ssec.wisc.edu/). The brownish outline is an automatically generated contour.

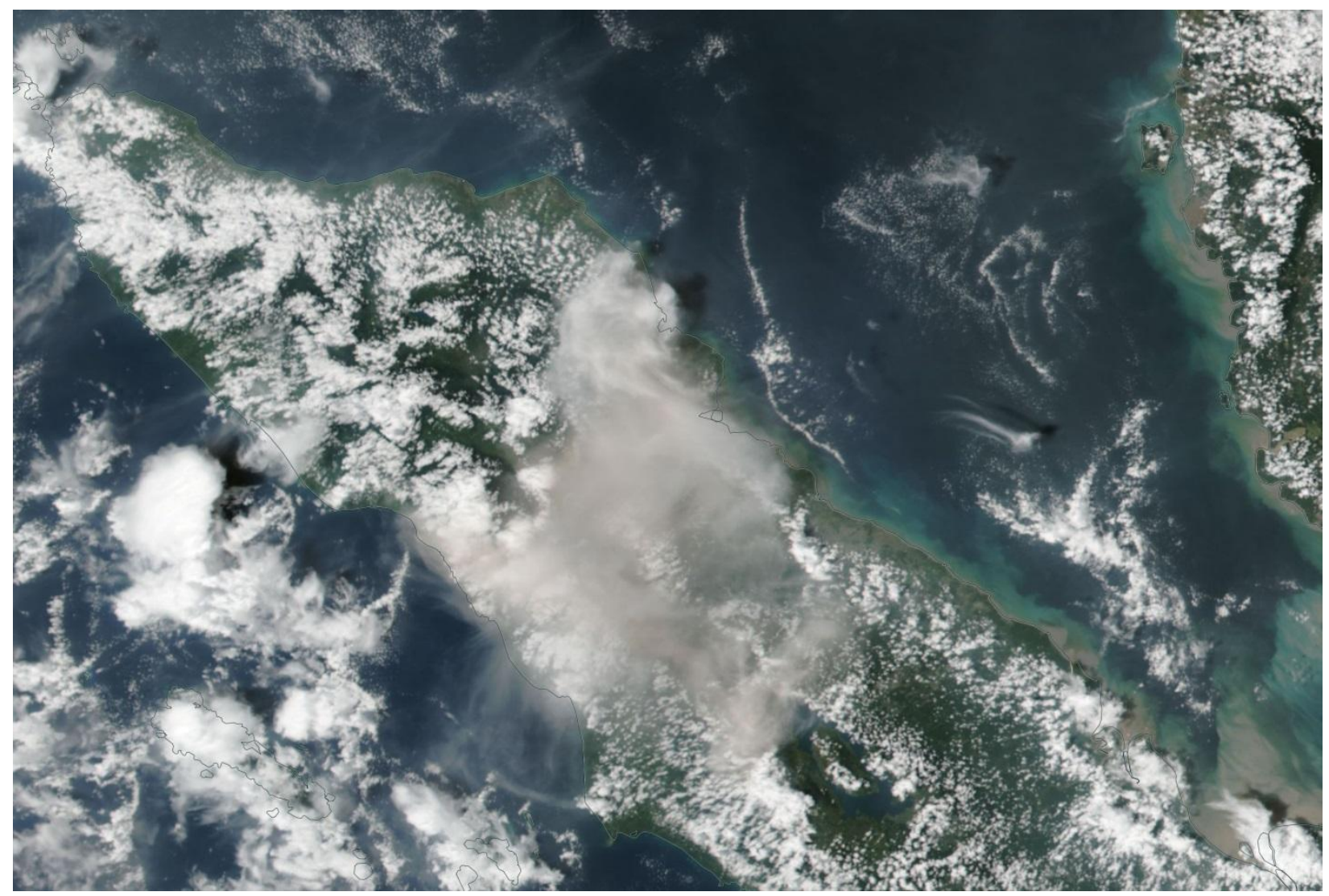

Figure S2a. MODIS-Terra pseudo visible color images on 19 February 2018 over northern Sumatra, approximately 10:30

15 local time. Image obtained from https://worldview.earthdata.nasa.gov/. 


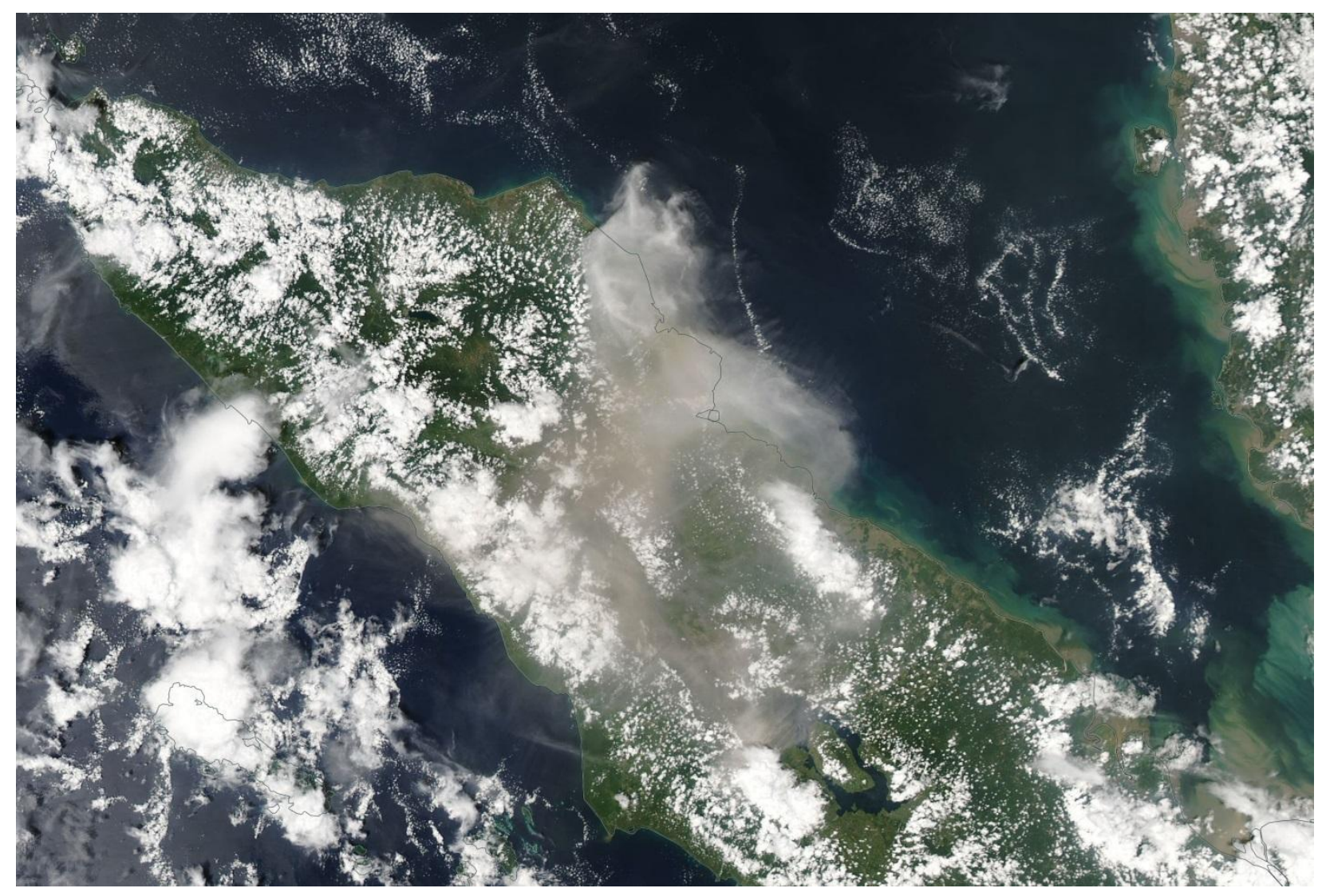

Figure S2b. As figure S2a but for the VIIRS satellite instrument and at approximately 13:30 local time. Image obtained from https://worldview.earthdata.nasa.gov/. 